\title{
DILEMAS DA PERFORMANCE NA ERA DO REGISTRO
}

\section{DILEMMES DE LA PERFORMANCE EN TEMPS D'ENREGISTREMENT}

\author{
João Paulo Leite Guadanucci ${ }^{1}$ \\ Suianni Cordeiro Macedo ${ }^{2}$
}

\begin{abstract}
Resumo: Parece haver consenso de que a prática artística da performance está ligada a duas características: sua permeabilidade em relação a realidade; e sua adesão a um determinado "aqui-agora", o que implica efemeridade. Vivemos, todavia, uma época marcada pelo imperativo do registro: a experiência das coisas do mundo sugere a aparente necessidade de captação a partir de dispositivos tecnológicos (sobretudo imagéticos). A performance acusa as consequências dessa circunstância, que impacta sua própria lógica de funcionamento e possibilidades de expressão. Este ensaio busca refletir até que ponto a mediação tecnológica e imagética coloca em xeque as potencialidades expressivas da performance. Para tanto, propõese uma reflexão sobre a influência da presença dos dispositivos de registro na relação entre performers e públicos; visa-se, ademais, apontar e categorizar as capturas que tais procedimentos implicam, valendo-se do conceito criado por Deleuze e Guattari (1997), cujo diagnóstico parece fundamental para permitir linhas de fuga.
\end{abstract}

Palavras-chave: Performance; registro; captura.

Resumé: Il semble exister consensus sur le fait que la performance art est liée à deux caractéristiques: sa perméabilité concernant la réalité; et sa adhésion à un certain «ici-maintenant», ce qui implique l'éphéméralité. Cependant, nous vivons à une époque marquée par l'impératif de l'enregistrement: l'expérience du monde suggère le besoin de le capturer par d'appareils technologiques (en particulier audiovisual). La performance montre les conséquences de cette circonstance, subi dans sa logique de fonctionnement et ses possibilités d'expression. Cet essai cherche à penser dans quelle mesure la médiation audiovisual remet en cause le potentiel expressif de la performance. On proposé une réflexion sur l'influence de la présence d'appareils d'enregistrement dans la relation entre les artistes et le public; en outre, il vise à souligner et à catégoriser les captures entrainées par telles procédures, en utilisant le concept de Deleuze et Guattari (1997), dont le diagnostic semble fondamental pour permettre des lignes de fuite.

Mot-clés: Performance; Enregistrement; Capture.

\section{O problema}

Um olhar sobre o panorama contemporâneo da performance revela um elemento cuja presença é eloquente: a preocupação com o registro audiovisual e fotográfico das ações. $\mathrm{Na}$ prática, decorre daí uma profusão de profissionais e equipamentos especialmente destinados a essa finalidade, competindo pelo espaço com artistas e espectadores. Essa tendência parece ter se tornado muito evidente nas últimas duas décadas; pode-se elencar um conjunto de motivações que a justificam, que vão desde o desenvolvimento tecnológico de equipamentos, das plataformas de difusão de conteúdos bem como a diminuição dos custos de produção de imagens aos interesses do mercado de arte e à modificação das estratégias de colecionismo.

\footnotetext{
${ }^{1}$ Mestre em História da Arte pela Escola de Comunicações e Artes da Universidade de São Paulo. E-mail: jplg1975@gmail.com.

${ }^{2}$ Doutora em Educação pela Faculdade de Educação da Universidade Estadual de Campinas. E-mail: suianni.macedo@gmail.com.
} 
Diante disso, interessa a esse artigo explorar as implicações da relação entre a performance e o registro fotográfico e videográfico, problematizando o papel de mediação exercido pelas imagens entre artistas e os públicos, além de buscar compreender os impactos de tal fenômeno tanto na criação artística como na maneira como os públicos se relacionam com as respectivas experiências estéticas.

Considere-se a afirmação recorrente segundo a qual a relação entre a performance e o registro se baseia na impossibilidade deste último dar conta das experiências disparadas pela ação. Ainda que se possa argumentar com justeza que a experiência da arte se dá no encontro do expectador com a obra e que, portanto, ela é um acontecimento, é na performance que a urgência do aqui-agora e do seu caráter irrepetível se faria sentir de modo intrínseco, como o ímpeto que impulsiona a própria linguagem artística. Essa é provavelmente a definição de performance que mais se aproxima de um consenso entre artistas e pesquisadores do campo das artes.

Nesse sentido, ao recusar a ideia de objeto material como modo de criação artística assim como a recusa da ideia de ensaio preparatório e de construção psíquica de uma personagem, ambas características das artes cênicas -, a performance projeta na trivialidade de movimentos corriqueiros, na aproximação a determinados processos de ritualização, na subversão de elementos espaço-temporais cotidianos e/ou no encontro imprevisível entre artista e públicos através da ação ao vivo, o centro da experiência estética.

Levando-se em conta que grande parte das tensões nas artes visuais do século XX se concentram na reprodutibilidade técnica - segundo diagnóstico de Benjamim (1987) -, no caso da performance, pode-se dizer que elas estão no cerne da problemática do arquivo. Parece, então, pertinente indagar em que medida, assim como a reprodubitilidade técnica modifica os significados das relações com os objetos materiais da arte, decorrem capturas e linhas de fuga da relação entre a performance e o aparente imperativo do registro, que modificam e mesmo transgridem os sentidos propostos nas ações, inventando outra performatividades insuspeitas dos artistas proponentes.

\section{Por que registrar?}

O posicionamento de Peggy Phelan, pesquisadora da performance, parte do pressuposto de que as estratégias de registro são pensadas numa perspectiva negativa na medida em que se supõe sua pretensão de reatualizar a posteriori o acontecimento performático. Como afirma Phelan:

A única existência possível da performance se dá no presente. A performance não pode ser salva, gravada, documentada ou participar de qualquer forma da circulação de representações de representações: quando isso acontece, já não se trata mais de performance. A performance ocorre num tempo que não pode ser repetido. Pode ser performatizada novamente, mas será então uma performance distinta da primeira. (1996, p. 146; grifo dos autores)

Entretanto, o cenário das últimas décadas nos sugere algo distinto: a onipresença de registro de performances é perpassada por uma pluralidade de motivações e objetivos, dentre os quais a ideia de gerar uma reprodução supostamente fiel ao evento presencial seria apenas uma das possibilidades. Face a essa constatação, valeria indagar de quais maneiras o registro de uma performance é pensado, começando pelo empenho em distinguir as motivações que ensejam os registros. À primeira vista, a motivação varia com o agente. Instituições culturais recorrem a registros das performances que acontecem em seus espaços ou que foram por estas subvencionadas tendo como principal moção a necessidade de comprovar seu envolvimento com a difusão artística e, por vezes, justificar o empenho de recursos econômicos, humanos ou estruturais. No caso do registro feito por iniciativa dos próprios performers, é costumeiro que o 
objetivo seja a constituição de portfólios ou currículos profissionais, o que está ligado à continuidade de suas respectivas vidas profissionais. Há, ademais, artistas que preveem o registro a fim de gerar arquivos que possam subsidiar pesquisas sobre as ações, revelando uma preocupação historiográfica compartilhada com estudiosos que se dedicam ao tema.

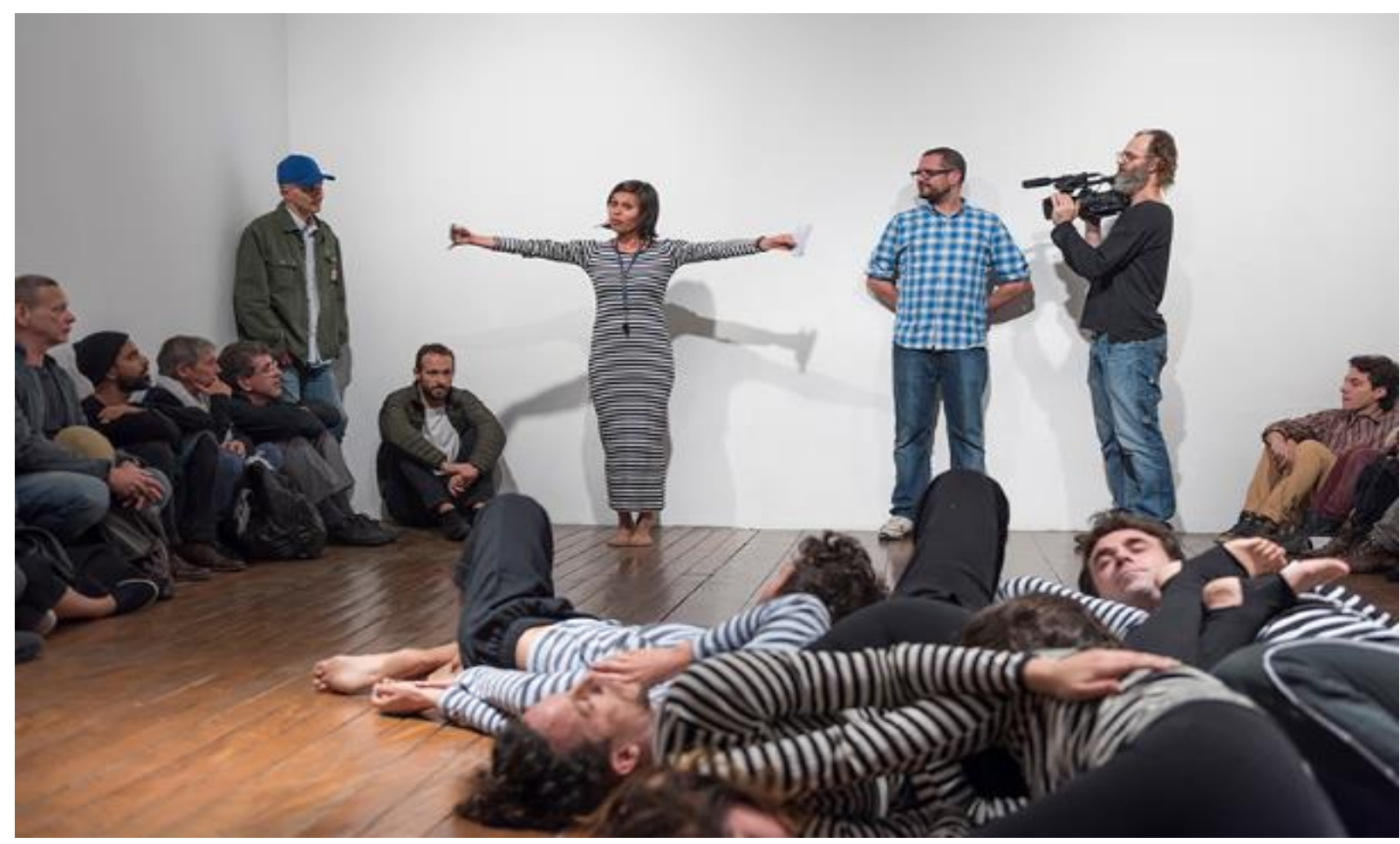

Performance Mikado Lilibeth Cuenca Rasmussen Galeria Vermelho, São Paulo/SP 2015

Fonte: https://www.galeriavermelho.com.br/8515/2015

As performances podem também ser registradas por artistas para servirem de matériaprima para suas próprias criações artísticas posteriores, ou para serem poeticamente retrabalhadas por outros criadores.

O registro pode ainda compor a lógica interna de uma determinada performance, fenômeno que cresceu à medida que aumentou a presença de dispositivos audiovisuais no cotidiano das pessoas. Aqui, a expressão "registro" soa inclusive inadequada, pois o que de fato ocorre é a captação/difusão de imagens dentro da própria poética apresentada pelo performer.

Por fim, vale lembrar que ações performáticas são registradas muitas vezes por mera empatia momentânea, hábito ou vínculo afetivo, tanto pelos espectadores como por pessoas envolvidas com a ação. Afinal de contas, captar as imagens de um determinado acontecimento tornou-se um comportamento típico do modo contemporâneo de apreender as coisas do mundo.

Há, portanto, uma variedade de ensejos que fazem com que os sons e imagens de uma performance sejam captados. Reduzi-los à indagação sobre a viabilidade ou não de reatualizar futuramente uma ação performática por meio de seu simulacro audiovisual é desconsiderar as complexas interrelações entre presencial e virtual nos dias que correm.

A compilação de motivos que podem redundar na captação audiovisual de uma performance, brevemente esboçada acima, sugere três categorias mais amplas:

1. Registro com destinação preponderantemente documental: relacionado à necessidade de artistas e/ou instituições de descreverem as características de uma ação, para fins 
profissionais, comprobatórios ou arquivísticos. Em geral, esse tipo de registro tende a evitar intervenções posteriores, bem como expedientes de edição que criem narrativas alheias àquela desenvolvida no momento da ação.

2. Captação "expressiva" do acontecimento: realizado principalmente pelos artistas, vale-se do trabalho de profissionais para enfatizar uma determinada opção estético-poética, por meio de movimentações expressivas de câmera, de recursos sonoros e imagéticos acrescentados em fases de pós-produção, de escolhas enfáticas de montagem e edição, entre outros artifícios. Nesses casos, há clara aproximação entre o registro da performance e as linguagens de vídeoarte ou cinema, não sendo raro que o material audiovisual seja tratado de modo relativamente autônomo, ganhando certa independência da performance que lhe deu origem.

3. Elemento integrante da poética da performance: há muitos casos em que a própria ação performática inclui dispositivos de captação e reprodução de imagens que, embora possam se utilizar de material audiovisual oriundo dos artistas performers e suas ações, não objetivam documentar a criação artística, já que fazem parte desta.

Quando são abordadas as possíveis contradições entre as ações performáticas e o registro, deve-se ter em mente as distinções acima propostas. Sem tal cuidado, arriscase misturar expedientes de naturezas diferentes. A hipótese que será desenvolvida daqui em diante, segundo a qual o tratamento inadequado dado às práticas de registro colocam em xeque a efetividade da performance como proposição artística, só adquire sentido quando o registro desempenha um dos dois primeiros papeis acima mencionados: registro com destinação preponderantemente documental ou captação "expressiva" do acontecimento. Se o registro fizer parte integrante do discurso estético, conforme aponta a terceira categoria esboçada, todos as peculiaridades ligadas à captação audiovisual dizem respeito exclusivamente às opções poéticas do artista.

\section{Embates e naturalização do registro}

O advento da performance no campo da arte - que se consolidou principalmente na passagem da década de 1950 para os anos 60, embora haja precursores ligados às vanguardas modernas - está relacionado a um determinado contexto cultural e político-econômico. Há certa convergência em torno da tese de que os artistas que, à época, se dedicaram a ações performáticas em diversas partes do mundo, como Europa, Estados Unidos, Japão e Brasil, respondiam a determinados impasses da arte moderna. E a principal resposta a tais impasses se deu a partir da ênfase no acontecimento, em detrimento da objetualidade da pintura e da escultura - uma passagem do "objeto-material para o objeto-relação", conforme síntese de Liliana Coutinho (2017, p. 129).

Meio século mais tarde, assiste-se a um quadro de institucionalização da performance, marcado de um lado pelo interesse de galerias, museus e colecionadores e, por outro, pela profissionalização de artistas. Em tal circunstância, o registro audiovisual e fotográfico adquiriu uma importância estratégica, já que parece capaz de ultrapassar precisamente o aspecto que, de início, servira como pedra de toque da linguagem que surgia: a adesão inelutável ao espaço-tempo do acontecimento.

Todavia, a crescente institucionalização da performance parece não ser suficiente para explicar o crescimento exponencial do registro em fotografia e vídeo. Verifica-se, do ponto de vista das coleções de diferentes instituições, outras formas de presença da performance para além de registros audiovisuais. Uma das curadoras da Tate Modern, Catherine Wood, destaca nesse sentido as mudanças que as ações consagradas à lógica do acontecimento e à adesão da experiência no tempo presente impuseram a própria noção de coleção e acervo da instituição. Numa entrevista concedida a Liliana Coutinho, a curadora aponta uma variedade de formatos 
presentes no acervo, tais como roteiros, instruções, partituras, fotografias, vídeos, instalações de adereços ou cenários. Wood salienta ainda que o percurso das curadorias de performance que tem traçado na instituição"faz parte também de uma estratégia persistente no que respeita ao acto de colecionar, reflectindo acerca de como o 'incolecionável' pode ser incorporado numa coleção." Segundo ela, a instituição incorporou a performance ao longo dos anos "numa prática mais alargada que não era necessariamente antigaleria e antimuseu [...] assumindo o ponto de vista da performance como atitude, ela pode modificar a nossa leitura do estatuto e do significado de qualquer das obras da coleção [...]". Uma pesquisa mais detida sobre a trajetória das coleções de instituições culturais e museológicas traria outros exemplos interessantes sobre como as instituições têm gerido acervos de obras vivas e evidenciaria que sua presença não se dá exclusivamente através de registros audiovisuais.

Assim, o excesso de registro audiovisual não parece se explicar exclusivamente pelas demandas do "sistema das artes", ainda que não se deve obviamente excluir a importância de sua participação nesse processo. O desenvolvimento de tecnologias do universo audiovisual, ademais, é um elemento fundamental a ser considerado no contexto que buscamos analisar. Novas tecnologias permitiram que as estratégias de registro fossem universalizadas, na medida em que barateou e simplificou procedimentos anteriormente inviáveis. Como consequência desse cenário, a presença de dispositivos e profissionais dedicados à captação de som e imagem não apenas espalhou-se por museus, galerias e centros culturais, além de espaços variados das cidades; ela aparentemente naturalizou-se. Nesse sentido, mais que falarmos na facilidade do acesso e na redução dos custos de execução dos registros audiovisuais, cabe destacar o surgimento de um outro regime visual, cuja ação tem modificado significativamente as relações entre pessoas e imagens. Isso significa que tais presenças são de algum modo esperadas e, em decorrência disso, toleradas e mesmo multiplicadas pelo público.

Entretanto, tal tolerância tem desdobramentos importantes. Negligenciar tais desdobramentos, que no limite podem inviabilizar a efetiva experiência da performance - essa é a hipótese desse artigo - é uma postura que só poderia ser compreendida quando eventualmente exista um cálculo segundo o qual os benefícios do registro superariam suas problemáticas implicações.

Trata-se de um cálculo cujos termos são desiguais. De um lado, há os alegados benefícios do registro, que já foram citados anteriormente, ligados à institucionalização das práticas, à profissionalização dos artistas e à preocupação das instituições culturais com a memória das ações por estas fomentadas. De outro lado, temos os impactos que o registro ocasiona nas ações performáticas.

Há diversas abordagens possíveis para o fenômeno do excesso de registros audiovisuais e fotográficos. Dentre elas, uma permite encaminhar reflexões sobre a própria lógica da performance. O que se visa nesse artigo não é identificar as causas do que estamos chamando de excesso de registro, mas uma investigação acerca dos impasses que o abuso de expedientes de registro documental implica para essa linguagem artística. Dito de outro modo: é legítimo sugerir que, em grande parte dos casos, o registro inviabiliza o acontecimento-performance?

No mais das vezes, não é dessa maneira que o registro é abordado. Reiteradas vezes pensou-se a questão a partir da possibilidade ou não de se dar perenidade a uma experiência em tese efêmera. Afinal, residiria precisamente na efemeridade, na adesão a um determinado aqui-agora, a peculiaridade da performance. É com base nessa adesão à temporalidade que Ana Pais procura defini-la, salientando que a performance "opõe-se ao paradigma da representação para criar formas de estar com os espectadores conviviais e reflexivas, na realidade do aqui-agora." (PAIS, 2017, p. 7). No mesmo sentido, o artista norte-americano Robert Morris, afirma acerca de seu trabalho que: 
o que desejo juntar, para o meu modelo de presentidade, é a inseparabilidade íntima da experiência do espaço físico e daquela de um presente continuamente imediato. $\mathrm{O}$ espaço real não é experimentado a não ser no tempo real. O corpo está em movimento, os olhos se movimentam interminavelmente a várias distâncias focais, fixando inúmeras imagens estáticas ou móveis. A localização e o ponto de vista estão constantemente se alterando no vértice do fluxo do tempo. (2006, p. 404)

Levando em conta tal perspectiva, o registro que pretende revivificar no futuro a ação do performer estaria fadado ao fracasso. Kristine Stiles destaca por sua vez, que o cerne da performance não está condicionada a existência de registros, que independe de qualquer prova ou testemunho da sua realização. Afirma Stiles que as performances "podem ser transmitidas por satélite e vistas por milhões, aparecer em discos laser interativos e tomar lugar na realidade virtual [...] podem ocorrer sem testemunhas ou documentação, ou elas podem ser amplamente registradas em fotografias, vídeos, filmes ou computadores" (1996, p. 680; tradução dos autores).

Se considerarmos que a captação audiovisual e fotográfica das performances, quando é realizada da forma que se tornou convencionalmente aceita pelo "sistema da arte", compromete inelutavelmente a experiência de artistas e espectadores, fica patente o desequilíbrio no jogo de prós e contras que se buscou esboçar. É sobre tal comprometimento que cumpre agora discorrer.

\section{Registro como captura}

Cena 1: Bairro central de uma grande cidade, marcado por vulnerabilidade social. Uma pessoa empurra uma grande pedra de gelo, de aproximadamente um metro de altura, pelas calçadas. Alguns transeuntes olham com atenção, por vezes crianças o perseguem, a maioria olha desconfiadamente. Uma ou outra pessoa saca seus aparelhos celulares para filmar o que julga inusitado. Há comentários jocosos e levemente agressivos. A situação se desenrola desse modo até que um indivíduo com uma grande câmera filmadora digital nos ombros, aparentemente profissional, é percebido. Ele está acompanhando, a alguns metros, a ação do empurrador de gelo. A reação das pessoas altera-se imediatamente. Alguém comenta, em voz alta: "deve ser uma pegadinha ou um artista da Globo".

Cena 2: Galeria de arte em bairro nobre de uma grande cidade. Festival de performances. Um homem, a priori identificado como artista, está em frente a uma mesa de madeira, na qual repousa um paralelepípedo. Munido de um maçarico, ele traça lentamente um círculo no tampo da mesa, ao redor do paralelepípedo, como se quisesse causar a queda do mesmo. Pessoas observam a ação, alguns em movimento, outros encostados nas paredes da sala. Uma mulher com uma grande câmera filmadora digital nos ombros e um homem com uma câmera fotográfica, ambos profissionais, movimentam-se freneticamente em torno do performer e dos objetos com os quais ele se relaciona. Quando eles param em determinado ponto, alguns espectadores reposicionam-se para continuar acompanhando a ação.

As cenas 1 e 2 aconteceram na cidade de São Paulo. Ambas ilustram os vários modos por meio dos quais o registro pode capturar o ato performático. A sugestão é pensar aqui a captura a partir do conceito criado por Gilles Deleuze e Felix Guattari (1997) para descrever o expediente de determinadas instâncias de poder - notadamente o poder estatal-capitalista em suas diversas manifestações - de converter qualquer modo de expressão insurgente denominada pelos autores como máquinas de guerra - a partir das possibilidades de significação que tal poder cria, reproduz e aceita como válidas, neutralizando desse modo o potencial revolucionário daquelas expressões. 
É útil pensar a captura em camadas. A primeira delas, mais visível e superficial, está relacionada à presença física das pessoas e equipamentos envolvidos na documentação da ação.

A fisicalidade inerente às estratégias de registro interfere de modo crucial no acontecimento performático. O tamanho, as configurações, os materiais e as cores da câmera, dos cabeamentos, de eventuais recursos de som e luz, bem como das pessoas que operam esse conjunto - tudo isso impede que, por razões óbvias, se ignore a presença desses elementos e dificulta que a performance apareça em sua integridade. Do espectador e do performer, exige-se que busquem esquecer os contornos não transparentes desses vultos que, não raro, são também móveis.

A partir da fisicalidade das pessoas e coisas empenhadas na captação audiovisual, um jogo de comparações se desenrola: avalia-se, inconscientemente, o tamanho do corpo do performer a partir do tamanho do conjunto câmera-tripé-profissional; a cor preta, padrão das roupas e equipamentos desse tipo de serviço, contrasta com as paredes brancas que são igualmente padrão em espaços da arte como galerias e museus. Em ambos os casos, a movimentação frenética dos profissionais do registro faz com que os ritmos presentes no ato performático sejam percebidos comparativamente àquela; as próprias ideias de proximidade e distanciamento, entram em colapso devido ao intruso encarregado de tudo documentar.

A captura físico-fenomenológica operada pelo registro, que coloniza todos os aspectos de performance pela sua eloquente presença, pode ser pensada como uma primeira camada de sucessivas capturas. De certo modo, devido a sua ênfase na aparência, ela prepara e, ao mesmo tempo, vela outras modalidades mais sutis de captura. Isso significa que o incômodo gerado pela presença física de seres estranhos à relação artista-público - que por vezes obriga os espectadores a se deslocar para assistir adequadamente à ação - é tão evidente que pode implicar um ocultamento de outras formas de captura.

Denominaremos simbólico-linguística a segunda camada de captura patrocinada pelos expedientes de registro. A particularidade desse tipo de captura é o poder dos símbolos mobilizados pelas práticas de registro de influenciar o contexto da performance, subvertendo o papel discreto que delas se esperaria. Isso se dá em dois âmbitos: um relacionado às pessoas e outro aos dispositivos tecnológicos.

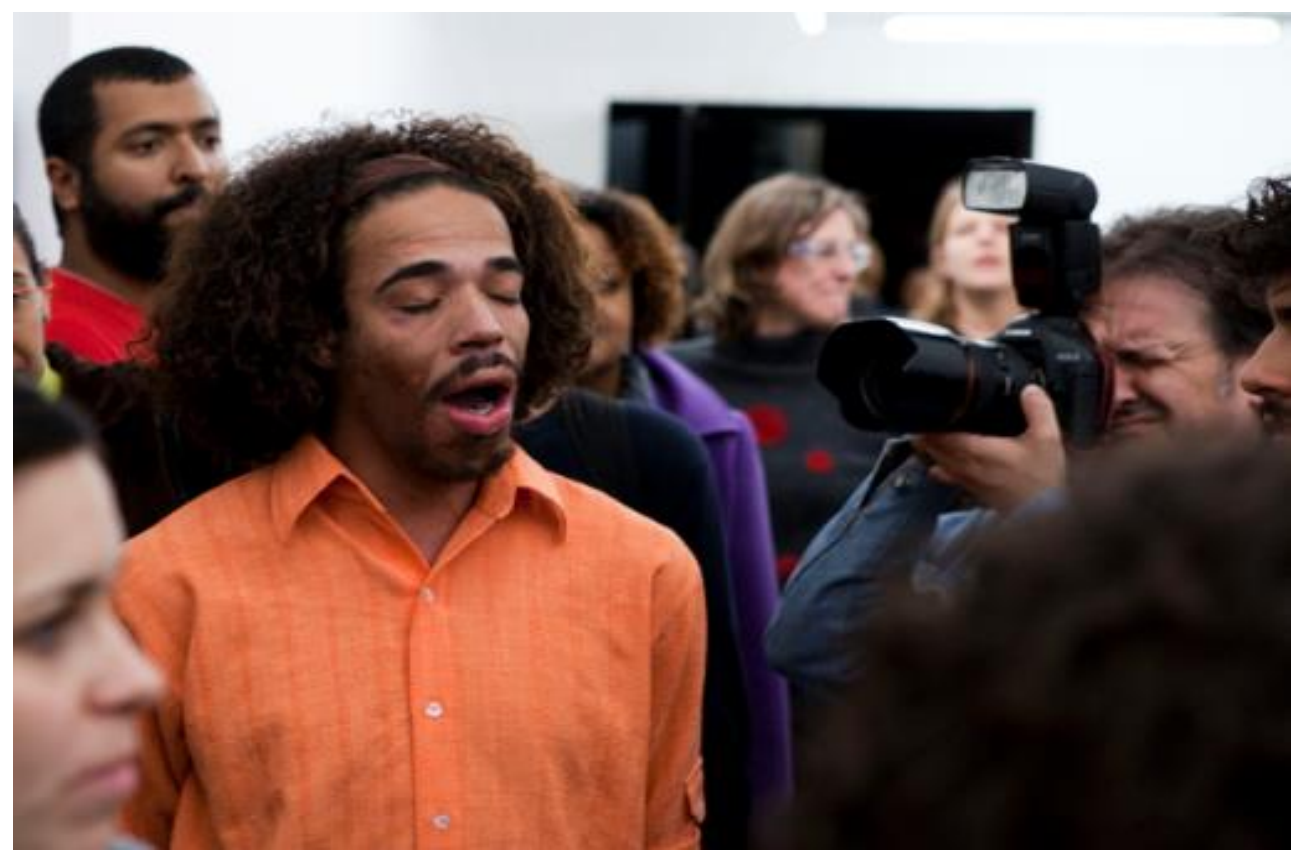

Performance $O$ nome. Maurico Ianês, Galeria Vermelho, São Paulo/SP, 2010

Fonte: https://www.galeriavermelho.com.br/1288/2010 
O registro de uma performance, quando se dá de forma oficial ou institucional (diferentemente das circunstâncias em que os públicos captam espontaneamente imagens com seus aparelhos de uso cotidiano), fica a cargo de indivíduos que, em geral, estão paramentados em consonância com a atribuição: roupas pretas ou no mínimo "neutras"; coletes e pochetes com lentes e apetrechos; elementos de identificação profissional, como crachás, inscrições nas roupas ou em bonés, entre outros signos. Esse conjunto de informações, associado às posturas, gestos e movimentações típicos de um técnico em ação, dá um tom de profissionalismo ao ambiente que, de diversas maneiras, contamina a ação artística que está sendo documentada.

Os equipamentos audiovisuais também impregnam a situação performática com seus símbolos. Nesse caso, predominam sinais ligados à tecnologia: modernidade, perfeição, automatismo, impessoalidade, assepsia, frieza, distância. Esse conjunto de sinais contrasta ou reforça, em maior ou menor grau, os sinais emitidos por todos os elementos presentes na performance, incluindo os corpos humanos. Objetos envelhecidos, artesanais ou rústicos, substâncias orgânicas ou naturais, tudo isso adquire uma ênfase suplementar num contexto habitado por câmeras de última geração, nas quais estão visíveis características como superfícies reflexivas, luzes, telas de alta definição, marcas e modelos impressos, entre outras.

Poder-se-ia avançar um pouco mais na exploração dessa segunda camada, tipificada por sua conotação simbólica, para incluir aqui os sentidos contextuais carregados junto com a imagem de uma câmera profissional operada por uma pessoa capacitada para tal. Nesse caso, esse amálgama ser humano-máquina traz consigo ideias difundidas pela produção audiovisual massificada, já que são vistos pelas ruas das grandes e médias cidades como representantes de canais de televisão ou internet, encarregados da elaboração de conteúdos para telejornais, novelas, seriados, filmes, comerciais e afins. Assim, ao serem identificados, tais personagens criam um hiato na realidade, impregnando o fenômeno que registram de inegável peculiaridade.

Diferentemente da primeira camada de captura, na qual os entes envolvidos no registro são abordados enquanto corpos físicos que interferem na experiência da performance, no caso da camada simbólico-linguística, os mesmos entes são abordados como instâncias que emitem signos a todo momento. Trata-se de uma ação menos evidente que aquela desencadeada pela captura física. Mas esta não é a derradeira camada: há de se considerar uma terceira categoria, ainda mais estruturante da realidade que aqui se busca descrever.

A sugestão é denominá-la captura político-institucional. Ela enfatiza o sistema de interesses e poderes, a rede de agendas mais ou menos explícitas que constitui o meio da arte e, mais amplamente, da ação cultural. Embora de natureza intangível, tal captura manifesta-se por meio de signos materiais e/ou visíveis: as pessoas e dispositivos comprometidas com a documentação das performances são, nesse ponto, decodificadas como agentes de (re)afirmação do sistema da arte.

Isso ocorre em algumas instâncias, a começar pela desenvoltura que marca a presença de profissionais ligados ao registro nos contextos em que performances são realizadas. Tal desenvoltura indica que, ao contrário do que poderia sugerir uma leitura "purista", segundo a qual seria esperado do ato do registro o maior grau possível de discrição, o que parece orientar tais práticas é a ideia de visibilidade: é fundamental que as câmeras e as pessoas que as operam sejam vistas e entendidas como legitimadoras do ato performático. Assim como a legenda afixada embaixo de uma pintura confere ao conjunto "pintura + parede + legenda" a rubrica "arte", a parafernália audiovisual pode funcionar como elemento que marca a fronteira entre uma ocorrência artística e um fato trivial.

Quando lemos essa circunstância sob um ponto de vista da história da performance, um contraste se impõe. Em suas primeiras décadas de existência, a linguagem representou um firme questionamento das convenções da arte do século XX, principalmente no que se refere à ênfase 
na autoreferencialidade objectual e, como consequência, na adesão dos artistas à circulação comercial de obras de arte. Entre as décadas de 1950 e 1980, a performance constituiu-se, em geral, como um ato que se opunha à recuperação e neutralização simbólica dos discursos artísticos engendrada pelo sistema de museus, galerias e publicações. Daí o caráter radical das proposições, seja na direção da tautologia, seja explodindo-se em rituais e sacrifícios.

A progressiva complexificação do sistema da arte, associada ao desenvolvimento, barateamento e massificação de tecnologias audiovisuais, alteraram aos poucos a situação. $\mathrm{Na}$ atualidade, a performance tornou-se uma modalidade estética entre as demais, alvo de pesquisas e disciplinas específicas no terreno universitário, objeto de publicações, festivais e editais, tema de debates sobre questões arquivísticas.

O registro parece ser o principal indicador desse estado de coisas. Ele não apenas torna possível a existência desencarnada da performance num momento pós-acontecimento como surge como indício de que o ato não se resume à sua aparição fenomenológica: ele é um representante do mundo da arte e, como tal, corre o risco de se tornar uma versão (um simulacro, inclusive) de si mesmo, traduzido pela institucionalidade da arte.

O fato é que tal tradução, que representa a mais contundente captura levada a cabo pela documentação audiovisual, se dá no momento mesmo do ato performático, aos olhos de artistas e públicos. Evidentemente, a captura acontece com maior contundência quando a performance ocorre em lugares que não compõem a priori o circuito da arte, como espaços do território urbano. Nesses casos, a presença visível dos aparatos retira o acontecimento performático da esfera anônima da urbanidade, rompe-lhe a opacidade e o transforma em bem cultural.

A depender do repertório dos públicos, tal bem será lido como "arte" ou como "coisa de televisão", o que mostra a proximidade entre essa camada de captura e a anteriormente abordada - o que mais não é do que testemunho das intersecções entre o mundo da arte e a esfera da mídia mais ampla, cujos procedimentos são crescentemente convergentes.

Aqui, as câmeras e seus operadores funcionam de maneira análoga àqueles reagentes químicos utilizados para evidenciar a presença de uma determinada característica numa substância, como sua acidez ou alcalinidade: elas permitem ver, na performance, a adesão à lógica da cultura institucionalizada.

Mesmo num cenário controlado, como é o caso de ações realizadas em museus, centros culturais ou galerias, as câmeras sublinham o enquadramento institucional imposto às performances, duplicando a influência já exercida pelas condições ambientais. Se é verdade que parcela importante da potência da performance em suas primeiras décadas advinha do caráter imediato das proposições, cuja originalidade residia na desconfiança em relação às mediação artísticas convencionais - papel, tela, tinta, plano, volume, gesto, figuração/abstração etc. -, a captura institucional patrocinada pelo registro elimina a hipótese de impacto sem mediações.

\section{A performance inviabilizada}

As três camadas de captura operam de modo orquestrado e tecem uma teia em torno do ato performático. Cabe perguntar se essa teia constitui apenas uma característica contemporânea que acabou se agregando ao discurso artístico, modificando-o - assim como as mudanças tecnológicas no universo das tintas e pigmentos alterou a lógica da pintura ao longo do século $\mathrm{XX}$ - ou se, pelo contrário, o invólucro que foi criado em torno da performance compromete a sua própria capacidade expressiva.

Lembrar que o surgimento da performance esteve relacionado à fadiga do sistema de arte nos anos 1950/1960 - cujos sintomas residiam na crescente tendência à autorreferência e na incapacidade de lidar com um contexto no qual os artistas haviam definitivamente perdido o 
monopólio da criação, manipulação e difusão de imagens - é contar apenas parte da história. Afinal, ao questionar os procedimentos artísticos à época consolidados, os artistas-performers colocavam em pauta a própria possibilidade de que atos criativos pudessem irromper diretamente na realidade, sem a obrigatória mediação da "instituição Arte". Daí seu parentesco eventual com modos de expressão ora ritualísticos, ora triviais, tributários de uma noção antropológica de cultura, na qual os fenômenos não estariam segmentados nos escaninhos e especializações que caracterizam a lógica ocidental.

Segundo tal perspectiva, não haveria aqui apenas um posicionamento contra determinado condição da arte em dado momento histórico, mas uma desconstrução da própria estrutura de ação e pensamento que dá coerência ao mundo no qual vivemos. Viria dessa postura a aparência de estranheza que acompanha grosso modo as situações performáticas, na medida em que os códigos mais fundamentais seriam por elas colocados em suspensão.

É lícito imaginar que muita coisa mudou desde a segunda metade do século XX, quando os artistas performers causaram abalos notáveis no circuito da arte. É admissível supor que a veia iconoclasta que permeava tais ações tenha se atenuado. Entretanto, é pouco provável esperar que todo e qualquer sinal que distinguia e dava caráter peculiar a esse tipo de expressão tenha se diluído, a ponto de ser considerado irrelevante ou descartável.

Pois é precisamente esse tipo de efeito que as camadas de captura empreendidas pelos expedientes de registro causam sobre a expressão performática. Diferentemente do que ocorre nos casos de linguagens como a pintura, escultura ou instalação, nas quais as relações internas são menos perturbadas por elementos externos, ou nas artes cênicas convencionais, onde aspectos estruturais (arquitetura, luz, localização de artistas e espectadores etc.) tendem a preservar/proteger o discurso dos artistas, as performances devem sua potência e sua fragilidade à mesma circunstância: sua permeabilidade em relação àquilo que a circunda.

\section{Referências}

BENJAMIN, Walter. A obra de arte na época de sua reprodutibilidade técnica. In: BENJAMIN, W. Magia e técnica, arte e política. 3. ed. Trad. Sergio Paulo Rouanet. São Paulo: Brasiliense, 1987. p. 165-196.

COUTINHO, Liliana. Quando a performance encontra o museu: em diálogo com Catherine Wood. In: PAIS, Ana (Org.). Performance na esfera pública: ensaios e páginas de artistas. Lisboa: Orfeu Negro, 2017. p. 129-138.

DELEUZE, Gilles; GUATTARI, Felix. Mil platôs: capitalismo e esquizofrenia, vol. 5. Trad. Peter Pál Pelbart e Janice Caiafa. São Paulo: Ed. 34, 1997.

MORRIS, Robert. O tempo presente do espaço. In: FERREIRA, Glória, COTRIM, Cecilia. Escritos de artistas: anos 60/70. Rio de Janeiro: Jorge Zahar Editora, 2006.

PAIS, Ana (Org.). Performance na esfera pública: ensaios e páginas de artistas. Lisboa: Orfeu Negro, 2017.

PHELAN, Peggy. Unmarked, the politics of performance. London/NY: Routledge, 1996. 
STILES, Kristine. Performance art. In: STILES, Kristine; SELZ, Peter (Org.) Theories and documents of contemporary art: a sourcebook of artists' writings. S/C: University of California Press, 1996. 